\title{
Relationship between Self-Efficacy, Transformational Leadership and Leader Effectiveness
}

\author{
Jana Mesterova, Jakub Prochazka, and Martin Vaculik \\ Department of Psychology, Faculty of Social Studies, Masaryk University, Brno, Czech Republic \\ Email: mesterova@gmail.com, jak.prochazka@mail.muni.cz, vaculik@fss.muni.cz
}

\author{
Petr Smutny \\ Department of Corporate Economy, Faculty of Economics and Administration, Masaryk University, Brno, Czech \\ Republic \\ Email: psmutny@econ.muni.cz
}

\begin{abstract}
The aim of this research is to empirically investigate the relationship between a leader's self-efficacy, transformational leadership and leader effectiveness. On the basis of the literature and current leadership research review, the theoretical model, in which transformational leadership mediates the relationship between a leader's selfefficacy and effectiveness, is proposed. The research was conducted within a three-month-long management simulation game at two Czech universities. A total of 32 leaders participated together with 604 subordinates. The criteria of leader effectiveness included leadership emergence and perceived leader effectiveness, both assessed by the leaders' subordinates, and objectively measured by group performance. For the assessment of the transformational leadership approach of leaders, we administered a questionnaire based on the transformational leadership theory to their subordinates. The self-efficacy of leaders was measured by a self-report questionnaire filled by leaders. The relationship of self- efficacy to transformational leadership was not supported, as well as the association between leader's self-efficacy and criteria of leader effectiveness. Therefore, the mediation model with transformational leadership in the role of the mediator was not accepted.
\end{abstract}

Index Terms-self-efficacy, transformational leadership, leader effectiveness, leadership emergence, group performance, business simulation

\section{INTRODUCTION}

In the current competitive environment, organizations attempt to be as successful as possible. Undoubtedly, one of the critical variables in determining the success or failure of an organization is leadership. Thus, leadership and its effectiveness have been the targets of considerable research and debate from which more questions have arisen. What makes some leaders more effective than others? Is there a characteristic that leaders of the most successful enterprises have in common? Do effective

Manuscript received April 26, 2014; revised July 5, 2014. leaders use specific practices in comparison with other less thriving executives?

In order to find certain answers to the aforementioned questions, this research attempts to empirically investigate the relationship between self-efficacy, transformational leadership and leader effectiveness. More specifically, we would like to examine the role of a leader's self-efficacy in determining leader effectiveness. In addition to this, we aspire to assess whether the transformational leadership style contributes to the association of self-efficacy with leader effectiveness.

\section{A. Leader Effectiveness}

Fundamental questions standing behind research of leader effectiveness are: what makes some leaders more effective than others and how can we predict their effectiveness. Even though answers to these questions are crucial, there has been no consensus among scholars. Similarly to the topic of leadership, there is neither a universally accepted approach nor definition. Certainly, the concept of leader effectiveness is difficult to define due to its complexity. It attempts to capture numerous components including multiple organizational contingencies and various personal and interpersonal behaviors. Therefore, we shall attempt to present different perspectives of leader effectiveness in this chapter and explain how its many components help us grasp this complex subject.

Different views of the effectiveness of leaders and its definitions are based on researchers' individual perspectives of leadership itself. For instance, Yukl [1] defines effective leadership as the process of influencing others to understand and agree about what needs to be done and how it can be done effectively, and the process of facilitating individual and collective efforts to accomplish the shared objectives. One inclusive definition of Cooper and Nirenberg [2] sees leader effectiveness as the successful exercise of personal influence by one or more people that results in accomplishing shared objectives in a way that is 
personally satisfying to those involved. From these two definitions, it is clear how their authors operationalize leadership but they do not respond to raised questions. However, these definitions make a point to stress the successful and satisfying outcomes effective leadership should bring. Cooper and Nirenberg [2] noted that although effective leadership requires the accomplishment of the organization's objectives that serve its vision and mission in a way that it satisfies those involved, both the degree to which objectives are accomplished and the satisfaction of those involved are quite subjective. Indeed, often inherent contradictions and conflicts make it virtually impossible to please everyone all the time. For instance, a company that is registering many new high-tech inventions while its stock price drops precipitously is experiencing a conflicted state which could be perceived by some as success (indicative of effective leadership) and by others as failure (indicative of ineffective leadership). Thus, the importance of considering different perspectives of leader effectiveness is very high and should not be omitted.

1) Factors determining leader effectiveness

In regards to leadership, we might ask why some people emerge as leaders or why some people are more effective than others in leadership roles. In the search for answers to these questions, the role of personality looms large. A number of empirical studies link personality traits, such as leader intelligence [3]-[5], emotional intelligence [6], dominance [7], [5], etc. with leader effectiveness. Of particular interest in recent years is the relationship between the Big Five personality traits (i.e., extraversion, agreeableness, conscientiousness, neuroticism and openness to experience) and leadership emergence, effectiveness or transformational leadership [8]-[10]. Although there were found significant correlations, this approach earned also a number of criticisms. From different perspective, another line of studies focuses more on the personality of followers, examining how it influences perceptions and evaluations of leadership.

As perhaps the most apparent individual difference, gender has captured the attention of researchers in domain of leader effectiveness. Many gender-based discussions in leadership research revolve around the question of whether men and women are equally effective leaders (for instance [11], [12]). In a quantitative review of the literature, Eagly, Karau and Makhijani [13] found that overall leader effectiveness was not dependent on leader gender, but men and women leaders perform differently under certain conditions.

Moreover, leaders' relationship with the followers can be considered as a factor determining effectiveness of leaders. Sweetland [14] found that ratings of leader effectiveness by subordinates and increases in group productivity were dependent on the interaction between supervisors and their subordinates. Chemers [15] asserted that good leader-follower relationships encourage increased feelings of leader-efficacy and group-efficacy and subsequently the collective effectiveness of the group. Poor relationships, on the other hand, had the opposite effect by introducing role ambiguity [16], alienation [17] and stress/strain [18].

Although it is clearly established that desired leader behaviors can differ between situations, there is little agreement about the nature of the contingencies and not a lot of research evidence about effectiveness in different situations. Aspects of the situation such as the nature of the task [19], [20], subordinate attributes (e.g., subordinate job and psychological maturity [21], subordinate effort and ability [1]), information possessed by subordinates [22] or type of work organization [1], [23], [24], belong to the most often suggested situational variables proven to determine effectiveness.

Among frequently considered determinants of leader effectiveness are also identity of leader and followers, self-concept, and social identity. For instance, van Knippenberg, van Knippenberg, De Cremer and Hogg [25] suggested that as followers identify more strongly with the collective (i.e., group, organization), the extent to which their leader is perceived to be groupprototypical (i.e., to represent the collective identity) becomes more influential in determining leader effectiveness. This research, among others, is based on social identity models of leadership (for overviews see [26]-[28]).

Charisma and its role as a determinant of leader effectiveness has been the subject of many studies recently. Theories of charismatic leadership stress that followers' perceptions of their leader are the ultimate determinant of leader influence [29]. Charismatic leaders communicate symbolically, use imagery, and are persuasive in communicating a vision that promises a better future. In this way, they create an intense emotional attachment with their followers [30]. Charismatic leadership theories are often associated with theories of transformational leadership. Charismatic leadership has much in common with transformational leadership. However, charisma is only a part of transformational leadership.

\section{2) Leader effectiveness criteria}

Despite the obvious interest of researchers or public in determining which leaders are effective and which are not, there has been no consensus on the most appropriate criteria of leader effectiveness among scholars. Lowe, Kroeck and Sivasubramaniam [24] distinguished two general categories of leader effectiveness criterions in their meta-analysis concentrated on effectiveness correlates. The first category, organizational measures of leader effectiveness, represents quasi-institutional measures of the effectiveness of leaders. Such measures include both hard measures (e.g., financial performance of work-unit, percentage of goals met) and soft measures such as supervisory performance appraisals. The second category use subordinate measures of effectiveness. However, subordinate effectiveness measures have been often criticized on the basis of mono-method bias, as well as for having a strong impact on findings regarding the leadership style-effectiveness relationship [31]. On the other hand, organizational measures, while perhaps reducing the common method bias problem [32], may not 
be especially valid measures of the effectiveness of the transformational characteristics of the leader, as they were often designed to capture primarily transactional outcomes [24].

Based on the current research trends [4], [33], we focus on three criteria of leader effectiveness: group performance, perceived leader effectiveness and leadership emergence. In respect to Lowe's, Kroeck's and Sivasubramaniam's [24] differentiation, we consider the group performance as so-called organizational effectiveness measures, while perceived leader effectiveness and leadership emergence as part of subordinate measures of effectiveness. We decided to use both categories of indicators of leadership effectiveness due to the single-method criticism mentioned above.

Similar to the differentiation between hard and soft organizational measures of leader effectiveness, group performance can be assessed objectively (units produced, sales volume, etc.) or subjectively (ratings of performance) [34]. For the purpose of this study, we operationalized group performance rather as objectively measured effectiveness of group/work-unit. Subordinate measure, perceived leader effectiveness, was considered as followers' assessment of leader effectiveness. Ford and Kiran [35] likewise saw perceived leader effectiveness as employees' general evaluation how a leader impacts a company. Second subordinate measure, leadership emergence, focuses on the degree to which an individual is viewed as a leader by others [36], [9], as well as the extent to which an individual comes to influence the group [37]. However, it should be noted that leadership emergence cannot be equated with leader effectiveness. Leader effectiveness focuses on a leader's performance in influencing and guiding the activities of a group toward the achievement of its goals [9]. Three used criteria describe different aspects of leader effectiveness. However, their correlation with each other is moderately strong to strong [33].

\section{B. Transformational Leadership}

Over the years, transformational leadership and charismatic leadership have been the focus of a great many research inquiries [38], which have helped shift the leadership paradigm to what it is today [39]. Three seminal works are widely credited with initially advancing theories of transformational leadership: Burns [40], House [41], and Bass [42]. Thanks to their contributions, transformational style of leadership has rapidly become the approach of choice for much of the research. Why such interest in transformational leadership? According to Bass and Riggio [43], with its emphasis on intrinsic motivation and on the positive development of followers, it represents a more appealing view of leadership compared to the social exchange process of transactional leadership. Perhaps it is because transformational leadership provides a better fit for leading today's complex work groups and organizations, where followers not only seek an inspirational leader to help guide them through an uncertain environment but where followers also want to be challenged and to feel empowered. Bass [44] specified that transformational leadership occurs when leaders broaden and elevate the interests of their employees, when they generate awareness and acceptance of the purposes and mission of the group and when they stir their employees to look beyond their own self-interest for the good of the group. Yukl [1] asserted that the transformational leader articulates the vision in a clear and appealing manner, explains how to attain the vision, acts confidently and optimistically, expresses confidence in the followers, emphasizes values with symbolic actions, leads by example, and empowers followers to achieve the vision. It is in line with Bass's components of transformational leadership. In his full-range leadership theory [42], he introduced four dimensions of transformational leadership: idealized influence, inspirational motivation, intellectual stimulation and individualized consideration.

Idealized influence or charisma, as Bass [42] originally defined it, is the emotional component of leadership, which is used to describe leaders who by the power of their person have profound and extraordinary effects on their followers. Attributional idealized influence refers to attributions of the leader made by followers as a result of how they perceive the leader. Behavioral idealized influence refers to specific behaviors of the leader that followers can observe directly, although both factors are essentially concerned with a leader's charismatic appeal [30]. Inspirational motivation is leadership that inspires and motivates followers to reach ambitious goals that may have previously seemed unreachable. Here, the leader raises followers' expectations and inspires action by communicating confidence that they can achieve these ambitious goals [45]. Intellectual stimulation is mostly a rational and nonemotional component. The leader appeals to followers' intellects by creating problem awareness and problem solving, of thought and imagination, and of beliefs and values [42]. Bass [42] stated that a leader using individualized consideration provides socioemotional support to followers and is concerned with developing followers to their highest level of potential and empowering them. In this instance, a leader gives individualized attention and a developmental or mentoring orientation toward followers. This outcome is achieved by coaching and counseling followers, maintaining frequent contact with them, and helping them to self-actualize [30].

\section{1) Transformational leadership effectiveness}

A substantial amount of evidence has been accumulated in support of the effectiveness of transformational leadership. There are numerous studies that support the effectiveness of transformational leadership over transactional leadership. For instance, results of meta-analyses [46], [24] supported the belief that transformational leadership was associated with work-unit and organizational effectiveness, suggesting the existence of a positive relationship between transformational leadership and effectiveness across the set of examined studies. Within these studies, idealized influence was the variable consistently most strongly related to leader effectiveness among the transformational leadership dimensions. Statistically significant 
relationship between leader effectiveness and transformational dimensions individualized consideration and intellectual stimulation were also found. All transformational dimensions were more highly associated with effectiveness than the traditional first order changes resulting from transactional behaviors [24]. However, if we are talking about effectiveness, types of criterions used for assessing leader effectiveness should be taken into account. Lowe, Kroeck, and Sivasubramaniam [24] reported that they have been different across studies in the meta-analysis. Some researchers used ratings of leadership style and ratings of leader effectiveness completed by subordinates, while other used organizational measures as their criterion. Both measures were rarely adopted in the same study.

Moreover, the effectiveness of transformational leadership can be operationalized also through the contribution of transformational leaders to follower commitment, involvement, loyalty, and satisfaction [43]. Transformational leaders can influence and motivate the behavior of employees in such a way that the resultant behavior has a positive impact on the organization. Research has shown that transformational leadership impacted commitment to the organization [47], [48] and to organizational change [49]. Bass and Avolio [50] claimed that transformational leaders influence subordinates by motivating and inspiring them to achieve organizational goals. Their direct impact on followers' empowerment and motivation was proven by Dvir, Eden, Avolio and Shamir [51]. By showing respect and confidence in their followers, transformational leaders create a greater degree of trust and loyalty of the followers to the extent that followers are willing to identify with the leader and the organization. This trust and loyalty result in followers willing to commit to the organization even under very difficult circumstances [52]. Other empirical studies also showed positive relationships between transformational leadership and personal outcomes such as satisfaction and performance of followers [53], [54], [48]. There is a clear need for greater attention in this area to understand the mechanisms through which transformational leadership influences personal attitudes in order to develop a more complete understanding of the inner workings of transformational leadership.

\section{Self-Efficacy}

Looking around, we can point to many examples of leaders in management or in political context who are particularly successful in their leadership roles. But what make these leaders more effective in comparison with other men or women in leading positions? An important contributor to their success might be their beliefs in their capability to perform a job or particular tasks, in other words their self-efficacy. These high-efficacy leaders may be better equipped to handle various situations and may transfer their efficacy to their followers, resulting in superior group performance. Thus, the purpose of this research is to examine the role of self-efficacy in leader effectiveness.
Self-efficacy is a key construct derived from Bandura's [55] social-cognitive theory. During the last decade, it has been studied extensively in organizational research [56][58]. Self-efficacy has been defined as beliefs in one's capabilities to mobilize the motivation, cognitive resources, and courses of action needed to meet given situational demands [59]. Chen, Gully and Eden [60] criticized this formulation for narrowing the focus of the researchers, who then conceptualize self-efficacy as a task-specific or state-like construct. More recently, researchers have become interested in the more trait-like generality dimension of self-efficacy, termed general selfefficacy [60]. General self-efficacy captures differences among individuals in their tendency to view themselves as capable of meeting task demands in a broad array of contexts [60]. So, it can be assumed that general selfefficacy is a belief in one's own ability to perform across different situations.

Various studies, for instance [61]-[63], suggested that general self-efficacy is a motivational trait and taskspecific or state-like self-efficacy is a motivational state. It is clear that both of them relate to the beliefs about ability to achieve one's goals, but they differ in scope. They both share similar antecedents such as actual experience, vicarious experience, verbal persuasion or psychological states [60]. Research has indicated that a strong relationship between general self-efficacy and task-specific self-efficacy exists [61]. Sherer et al. [64] asserted that this tendency to feel efficacious across tasks and situations (i.e., general self-efficacy) spills over into specific situations. In regard to leaders, we might say that their general self-efficacy refers to their beliefs in their general ability to lead. The task-specific self-efficacy of leader might be, for instance, the leader's belief in his or her ability to facilitate efforts of followers to accomplish the project.

\section{1) Leader's self-efficacy and leader effectiveness}

Given that leadership roles in organizations are becoming increasingly broad, complex, and demanding, high general self-efficacy of their chief executives may be a valuable resource for organizations. It can maintain leaders' work motivation throughout rapidly changing and stressful job demands or circumstances and buffer them from the potentially demotivating impact of failure [60]. On the basis of the theory of self-efficacy [56], we can expect leaders with greater general self-efficacy to be more effective leaders, because they are inclined to expend greater efforts to fulfill their roles across situations and to persevere longer when faced with difficulties [65]. Even though Bandura [56] did not refer to the concept of general self-efficacy in his theory, one may assume that a leader's belief in his or her ability to perform across variety of situations plays an important role in his or her effectiveness. The label of general selfefficacy is not seen in leader effectiveness literature often. However, according to the research [61], [64], we might assume that general self-efficacy is closely related to different domain-specific self-efficacies. In the context of leadership, relevant domain-specific type of self-efficacy might be leadership self-efficacy, defined by Chemers, 
Watson, and May [66] as perceived capabilities of the individual to perform functions necessary to accomplish specific leadership roles effectively.

Despite the common sense relevance of a leader's perception of his or her capabilities to perform effectively to leader effectiveness, only a limited number of studies have examined this relationship. Perceived leader effectiveness, one of the criteria of leader effectiveness, was linked to leadership self-efficacy in the research of Chemers, Watson, and May [66]. They found that Reserve Officer Training Corps cadets who had higher levels of leadership self-efficacy were given more positive leadership ratings by their superiors, peers, and trained observers in a 6-week leadership training camp. Paglis and Green [67] similarly found that managers who displayed higher leadership self-efficacy, whose confidence in giving direction was greater, and those who gained commitment, were rated by their subordinates as having made more attempts at leading change. Therefore, they found them to be better leaders.

Criterion of leader effectiveness most often associated with general or leadership self-efficacy is leader and group performance. In their laboratory experiment, Kane, Zaccaro, Tremble, and Masuda [68] demonstrated that leaders with high leadership self-efficacy set higher goals and had better task strategies, which in turn led to better group performance. Chemers [69] asserted that leadership self-efficacy beliefs influence the choices leaders make and the courses of action they pursue in order to accomplish tasks. He claimed that leaders' low leadership self-efficacy affects their ability to handle challenging tasks and solve a problem.

Therefore, they fail at completing their tasks. Thus, their low leadership self-efficacy affects their performance and in turn performance of their followers. Wisner [70] indicated that high levels of leadership selfefficacy improved their effectiveness as leaders. She found that a leader's leadership self-efficacy had a significant effect on the efficacies of his or her followers, which in turn resulted in higher performance of a group. Research of general self-efficacy in association with performance can be found mostly outside the leadership context. For instance, Raub and Liao [71] found that the general self-efficacy of employees predicted their performance and proactive customer service. Messer [72] investigated whether a relationship existed between general self-efficacy, academic performance, job performance and attrition of novice Army mechanics. His findings indicated that general self-efficacy was a good predictor of academic performance. The author of the study asserted that an understanding of this relationship would be a valuable asset for organizations, which would be able to reshape job requirements, hiring, training programs, and job assessment on the basis of the findings. Furthermore, the study found that training improved general self-efficacy of respondents [72].

In addition to this, the role of self-efficacy as a mediator of relationship between personality traits and work-related performance has been the subject of various studies. Many researchers work in their studies with the term self-efficacy exclusively. In general, we can say these authors' understanding of self-efficacy is mostly based on Bandura's [56] original concept of self-efficacy as task- or situation-specific. Martocchio and Judge [73], for example, asserted that task-specific self-efficacy represented the mechanism through which the generalized tendencies of conscientiousness were linked to performance. Chen, Casper, and Cortina [74] tested a meta-analytic model to determine whether self-efficacy mediated the relationship of cognitive ability and conscientiousness to job performance (they considered both, general and task- specific self-efficacy). These authors found that the mediation depended on job complexity. Mediation was stronger for simple jobs than for complex ones. Moreover, the study of Judge et al. [34] examined contribution of self-efficacy (as proximal variable) to work-related performance controlling for personality, intelligence and job or task experience. Their presumption was that a relationship of three distal characteristics cognitive ability, personality (the Big Five traits) and experience with work-related performance was mediated by self-efficacy. According to the results of their meta-analysis, they asserted that self-efficacy predicted performance in jobs or tasks of low complexity but not those of medium or high complexity, and selfefficacy predicted performance for task but not job performance. Their results also suggested that the predictive validity of self-efficacy was attenuated in the presence of individual differences, though this attenuation did depend on the context. Results of these studies implied that job/task complexity was a potential moderator of self-efficacy [74], [34], [58]. Another potentially important moderator of self-efficacy predictive validities is feedback. One would expect selfefficacy to be more valid when such judgments were informed by feedback on the performance of the task, especially when the feedback is delivered in a timely manner [56]. If we take into consideration CEOs, we may expect them to be informed about progress regularly during the task-solving process. Thus, they should receive feedback on a regular basis. Beyond the theoretical variables discussed above, measurement and study characteristics also may moderate the self-efficacy performance relationship. One such moderator is the measure of self-efficacy [34].

2) Role of self-efficacy in transformational leadership effectiveness

The role of self-efficacy in transformational leadership effectiveness has been usually studied from the perspective of employees' self-efficacy, which was enhanced by leader's transformational approach [75], [76]. However, there is very little research on the role of the self-efficacy of leaders in transformational leadership effectiveness and only a limited number of studies have researched the link between leader's self-efficacy and transformational leadership [77].

Existing theories support the idea that a leader's selfefficacy may be related to behaviors indicative of transformational leadership. Bandura [56] asserted that high levels of efficacy seem to be associated with higher 
levels of performance on all types of tasks in many different realms. This effect is partly associated with the influence which self-efficacy has on personal choice. Individuals who feel highly efficacious regarding a particular task will be more likely to choose to perform that particular task, set high performance goals, and in turn exhibit higher performance [56]. Transformational leadership is traditionally associated with challenging the status quo and instilling confidence in followers that they can achieve higher levels of performance [78]. It follows that the leader's own efficacy may be an important antecedent of transformational leadership, as individuals with low levels of efficacy are not likely to take the initiative in challenging situations and persuade others to do the same.

3) Self-efficacy, transformational leadership and leader effectiveness

Based on theories of self-efficacy [56], transformational leadership [42] and conducted research connecting these two constructs (e.g., [75], [79]), we can assume that they are related. Even though there has been little literature linking self-efficacy of leaders to transformational leadership style, for instance [80], [77], one can draw the conclusion that a leader's higher levels of efficacy may lead to higher levels of transformational leadership. Thus, we hypothesize that there should be a strong relationship between the two.

Hypothesis 1: Leader's self-efficacy is related to the extent which the leader exhibits transformational leadership.

On the basis of the existing research and Bandura's theory of self-efficacy [56], it can be expected leaders with greater self-efficacy will be more effective leaders, because they are inclined to expend greater efforts to fulfill their roles and to persevere longer when faced with difficulties [65].

Leadership emergence, perceived leader effectiveness and group performance have appeared to be powerful criterions for leader effectiveness. Therefore, we hypothesize a leader's self-efficacy to be significantly related to leader effectiveness, with leadership emergence, perceived leader effectiveness and group performance as leader effectiveness criteria.

Hypothesis 2: Leader's self-efficacy is related to leader effectiveness.

Although several studies found a relationship between self-efficacy and various leader effectiveness criteria [81] [82], the potential mediating effects of transformational leadership were not considered. One of the exceptions is research of Quigly [77], who tried to prove a mediating effect of transformational leadership on the relationship between a leader's efficacy and team efficacy, which then might translate into performance. However, the mediating effect was not confirmed.

We think that there is a good reason to believe that a leader's self-efficacy is positively associated with leader effectiveness and the extent to which the leader exhibits transformational leadership may play an important role in this link. Leaders are likely to convey their efficacy to their followers through their behaviors. To the extent that these behaviors help motivate followers and are indicative of the confidence the leader has, they may be the way in which the level of a leader's self-efficacy is made clear to followers-which is then likely to result in higher levels of group performance, leadership emergence and perceived leader effectiveness. Therefore, we hypothesize that transformational leadership is a mediator of the relationship between self-efficacy and leader effectiveness.

Hypothesis 3: Transformational leadership mediates relationship between self-efficacy and leader effectiveness.

\section{METHODS}

Our research was conducted within a standardized management simulation game. The management simulation game was played by the students of the Masaryk University in Brno and the University of Economics in Prague as a part of their lessons. During one semester, the students of each seminar group (approximately 20 students) represented a management of a fictional car factory, which sold its products on a computer simulated market. Every car factory was led by a CEO, who the students elected shortly after the beginning of a semester. Students were rewarded with fictional money during the game, based on which they were awarded the final grade at the end of the semester. The CEO had a great power which might be delegated to his or her associates. For example, the CEO had the final say in a decision on the organizational structure of a company, the division of work, the dismissal of employees, the recruitment of employees from other seminar groups and also in the distribution of (fictional) money among players. During the game, students had many opportunities to influence the profitability of their companies. They decided on the number of cars produced in each round, optimized production costs, invested in research, determined the basic car equipment, created marketing documentation and financial statements, made analyses of financial markets and negotiated loans with banks. Given the variety of tasks in the operation of a company, they needed to involve as many students as possible, motivate them and coordinate their work. CEOs were receiving feedback about the profits of their fictional companies on regular basis throughout the duration of the simulation game. The managerial game faithfully simulates an environment of a real economy and also offers the possibility to compare a large number of homogeneous companies [83].

The method of management simulation game was chosen for several reasons. Firstly, the use of the management simulation game reduces the impact of external variables. While in a real environment, competing companies have a different property structure, history, various political ties and a different product from the beginning. The management simulation game allows a putting of all the companies on the same starting linestarting as same-size companies economically, with approximately the same number of employees, with the same product in the same market. Thus, the possible 
influence of the perception of the company manager and the results by the subordinates is reduced. Furthermore, thanks to the involvement of students, the management of a company has approximately the same knowledge and experience. The environment of the management simulation game enables to better monitor the impact of variables related to the characteristics of people in the fictional companies, especially the impact of the chief executive's characteristics. The economic results of the monitored companies could be then compared, giving the management simulation game advantages over research in real-world conditions. Secondly, an access to all data and to all participants is guaranteed for the organizers of the management simulation game. In comparison with the real-world conditions, the simulation game allows for an obtaining of a large amount of data for the creation of complex models and also ensured a high return rate of questionnaires. Thirdly, unlike short-term simulations, the three-months-long management simulation game makes it possible to monitor the long-term effects of quasi-independent variables. This is important because the CEO may, through his or her personality and attitude, influence their subordinates for relatively long time.

\section{A. Participants}

A total of $32 \mathrm{CEO}$ /leaders were selected from fulltime students of bachelor and masters programs at the Masaryk University in Brno (13 CEOs, namely 41\%) and at the University of Economics in Prague (19 CEOs, $59 \%$ ). The average age of the CEOs of the 32 fictional companies was $21.4(S D=1.13)$. Most of the leaders were men (72\%). Each CEO was evaluated by an average of $17.42(S D=3.32)$ subordinates.

The CEOs/leaders were evaluated by a total of 604 respondents, their subordinates, who were, at the time of our study, also the full-time students of bachelor and masters programs at the aforementioned universities (259 respondents, $43 \%$ in Brno; 345 respondents, $57 \%$ in Prague). The subordinates were employees of the 32 fictional companies within the management simulation game, and they held various positions except for the CEOs' positions.

\section{B. Measures}

\section{1) Self-efficacy}

For the purpose of this research, we utilized the general Self-Efficacy Scale developed by Sherer et al. [64]. This 17-item scale measures a general set of expectations that the individual carries into new situations [64]. A sample item from the general Self-Efficacy Scale is "If I can't do a job the first time, I keep trying until I can."

Respondents answered using a 5-point Likert response ranging from "strongly disagree" to "strongly agree". Scores range between 17 to 85 and higher scores indicate greater self-efficacy. Sherer et al. [64] reported an internal consistency with Cronbach's alpha reliability coefficient of 0.86 . The internal consistency reliability for the general Self-Efficacy Scale in organizational research has been moderate to high ( $\alpha=0.76$ to 0.89 ; e.g., [84], [62], [85]). The general Self-Efficacy Scale has demonstrated construct validity correlating moderately with several achievement-related demographic variables such as military rank and educational level [64] and with such outcomes as leader emergence [85], job search decisions [84] or the number of training and development courses attended [86].

\section{2) Leader effectiveness}

The criteria of leader effectiveness included leadership emergence and perceived leader effectiveness, both assessed by the leaders' subordinates and objectively measured by group performance.

For the assessment of the leadership emergence, the five- item-questionnaire was used. Items were formulated to capture whether the leader has been considered as a good or a suitable leader by the followers (subordinates), whether they have perceived him or her as a "leader type" or whether his or her role as a leader has left a positive feeling in them. Each item represents a different perspective of leadership emergence, i.e. "Throughout the game, he/she was a real leader (leader and driving force) of our group" or "I felt respect toward him/her." The internal consistency reliability for the leadership emergence items was excellent $(\alpha=0.97)$. Criterion validity was confirmed by comparison with transformational leadership scale. For each of the aforementioned items, respondents could choose whether an item "reflects", "partially reflects" or "does not reflect" the perception of the CEO during the management simulation game. These answers were coded $2 ; 1 ; 0$. The variable leadership emergence was calculated as the average rating from all subordinates in all five items. Thus, it can acquire values from 0 to 2 .

To assess the perceived effectiveness of leader, two items were utilized. The items allowed respondents (subordinates) to assess the impact of the CEO of their firm in terms of effectiveness of the results ("He/she successfully guided our seminar group through the game") and effectiveness of the process ("Our company worked effectively under his/her leadership"). Internal consistency of perceived leader effectiveness items was excellent $(\alpha=0.96)$. Criterion validity was confirmed by a comparison with transformational leadership scale. The procedures of item coding and counting of the variable perceived leader effectiveness were the same as for the leadership emergence. Thus, the respondents might have chosen whether each item reflected, partially reflected or did not reflect the perception of the CEO during the management simulation game (answers were coded as 2; $1 ; 0)$. The variable perceived leader effectiveness was calculated as the average rating from all subordinates in all items. Thus, this variable acquired values from 0 to 2 .

The performance of the group was measured by the profitability of each fictional company during the entire management simulation game. At the beginning of the simulation game, all companies faced comparable conditions. Their performance was assessed on the basis of their profits during the seven game rounds. However, while companies were operating in different markets, they might have slightly different conditions during the game. Therefore, the performance of the company was 
assessed relatively to the average profitability on the relevant market. We calculated the variable group performance as the accumulated profit of the enterprise throughout the game, divided by the average profit of the companies on the market.

\section{3) Leadership style}

Since there is no Czech translation of the Multifactor Leadership Questionnaire, we used The Leadership Style Questionnaire to measure leadership style. It is an original, unpublished Czech method that has been validated on a sample of 1,093 Czech leaders and their followers. This questionnaire captures the transactional and transformational approach to leadership. It contains eight scales, which correspond to the four components of transformational leadership (charismatic behavior, inspirational motivation, intellectual stimulation, and individualized consideration), the three components of transactional leadership (contingent reward, active management by exception, passive management by exception) and the absence of leadership. Four scales of transformational leadership can be combined into a single internally consistent transformational leadership scale. Our research worked with transformational leadership scale exclusively (data obtained from other four scales are not subject of this research).

The questionnaire contains 32 items. Respondents answered using a 7-point Likert response ranging from "never" to "always". Some examples of items are "He/she takes responsibility for group's results" or "He/she makes it clear that he/she believes in team success."

The confirmatory factor analysis showed excellent fit indices. The questionnaire's CFI 0.96 exceeded the recommended value and RMSE 0.05 was lower than the recommended 0.06. The questionnaire has a good reliability. The internal consistency of all transformational scales is Cronbach's $\alpha>0.88$. For the split half reliability, the Guttman coefficient was always greater than 0.85 . Criterion validity was confirmed via comparison with answers to questions assessing leader emergence and perceived leader effectiveness. Transformational leadership scales have moderate to strong relationship with both criteria. Individual scales of transformational leadership correlate among each other and are positively associated to the contingent reward and negatively to the absence of leadership.

\section{Procedure}

Data were collected over two consecutive semesters (spring 2013 - fall 2013) as a part of a broader ongoing research. In the spring semester, 10 fictional companies took part in the research within the simulation game, and 22 fictional companies participated during the fall semester. The companies were divided into two to three markets in which they competed, while there were always seven to eight businesses on the market. At the end of the management game, the students/subordinates were asked to anonymously complete questionnaires in which they evaluated a) the transactional-transformational leadership style of the CEO, b) the effectiveness of the CEO, c) the managerial skills of the CEO (the analyses of transactional leadership style and managerial skills are the subject of another research). They were also requested to report information about their position and responsibilities in the management simulation game, which were needed for further analysis. Filling the questionnaires might have helped students to receive a better mark. In order to prevent students from answering randomly, their filling time was measured. A total of 712 students were asked to complete the questionnaire for the assessment of their CEOs. Of 634 students, which submitted the questionnaire, 10 were excluded from further data processing. Seven respondents were eliminated due to the filling time less than four minutes (time needed to read it only). Three respondents, which attended less than three meetings and therefore were not able to adequately evaluate their CEO, were disregarded as well.

A total of 37 chief executives were asked to take part in the research, from which 32 submitted the questionnaire. At the end of the management game, CEOs took part in the psychological testing, where the Self-Efficacy Scale, intelligence test and personality questionnaires were administered (intelligence test and personality questionnaires were not the subject of this study). For their participation and their approval to use data for the research, the CEOs received a report with the results of the psychological assessment.

After the end of the semester and the game, the economic results of the individual enterprises were investigated, thus information on group performance was obtained. Thanks to the use of the management simulation game, we were able to collect data about leaders' self-efficacy, transformational leadership style and leader effectiveness quickly and easily.

\section{RESULTS}

The following report of results begins with the descriptive statistics. We then present the results of hypotheses testing while using correlation and mediation analyses.

\section{A. Descriptive Statistics}

Table I presents the means, medians, standard deviations $(S D)$, minimums and maximums for the study variables. Table II presents the intercorrelations among all variables. Moreover, we tested our data for normality. For the assessment of normality, we used the ShapiroWilk Test [87] as it is appropriate for small sample sizes. According to the results ( $\mathrm{p}$-values ranged from 0.16 to 0.92) and visual inspection of the histograms, normal QQ plots and box plots, we can conclude that the data were approximately normally distributed.

\section{B. Hypotheses Testing}

Hypothesis 1 stated that self-efficacy is related to the extent to which the leader exhibits transformational leadership. Table III presents the intercorrelations between general self-efficacy and the subdimensions of 
the construct of transformational leadership. Pearson correlation coefficients $(r)$ are in the table.

TABLE I. MEANS, MEDians, Standard DeViations, Minimums AND MAXIMUMS OF STUDY VARIABLES

\begin{tabular}{|c|c|c|c|c|c|}
\hline Variable & Mean & Median & $S D$ & Min & Max \\
\hline Self-efficacy & 70.53 & 71.00 & 7.74 & 55.00 & 91.00 \\
\hline $\begin{array}{c}\text { Transformational } \\
\text { leadership }\end{array}$ & 84.92 & 84.88 & 6.88 & 65.55 & 97.59 \\
\hline $\begin{array}{c}\text { Charismatic } \\
\text { Behavior }\end{array}$ & 23.10 & 23.6 & 1.78 & 16.91 & 25.91 \\
\hline $\begin{array}{c}\text { Inspirational } \\
\text { Motivation }\end{array}$ & 22.75 & 23.38 & 2.16 & 17.82 & 26.71 \\
\hline $\begin{array}{c}\text { Intelectual } \\
\text { Stimulation }\end{array}$ & 21.76 & 21.26 & 1.90 & 18.63 & 25.48 \\
\hline $\begin{array}{c}\text { Individualized } \\
\text { Consideration }\end{array}$ & 17.39 & 17.30 & 2.3 & 12.18 & 21.73 \\
\hline $\begin{array}{c}\text { Leadership } \\
\text { emergence }\end{array}$ & 1.38 & 1.36 & 0.33 & 0.36 & 1.95 \\
\hline $\begin{array}{c}\text { Perceived leader } \\
\text { effectiveness }\end{array}$ & 1.51 & 1.56 & 0.37 & 0.568 & 2.00 \\
\hline Group performance & 1.80 & 1.40 & 0.36 & 0.24 & 1.99 \\
\hline
\end{tabular}

TABLE II. INTERCORRELATIONS OF STUDY VARIABLES

\begin{tabular}{|l|c|c|c|c|c|}
\hline Variable & 1 & 2 & 3 & 4 & 5 \\
\hline $\begin{array}{l}\text { 1. Self-efficacy } \\
\begin{array}{l}\text { 2. Transformational } \\
\text { leadership }\end{array}\end{array}$ & - & -0.01 & 0.08 & 0.00 & -0.11 \\
\hline $\begin{array}{l}\text { 3. Leadership } \\
\text { emergence }\end{array}$ & 0.08 & $0.76^{* *}$ & - & $0.75^{* *}$ & $0.51^{* *}$ \\
\hline $\begin{array}{l}\text { 4. Perceived leader } \\
\text { effectiveness }\end{array}$ & 0.00 & $0.68^{* *}$ & $0.75^{* *}$ & - & $0.84^{* *}$ \\
\hline $\begin{array}{l}\text { 5. Group } \\
\text { performance }\end{array}$ & -0.11 & $0.35^{* *}$ & $0.51^{* *}$ & $0.84^{* *}$ & - \\
\hline
\end{tabular}

Notes: $* \mathrm{p}<.05, * * \mathrm{p}<.01$

Table III shows that self-efficacy was not significantly correlated with any subcategories of the transformational leadership in our research. Of the four dimensions of transformational leadership, two acquired negative values. To conclude, Hypothesis 1 was not supported.

Hypothesis 2 stated that the self-efficacy of leaders is related to leader effectiveness. Table II presents Pearson correlation coefficients among self-efficacy and leader effectiveness criteria (leadership emergence, perceived leader effectiveness and group performance). Inconsistent with Hypothesis 2, there were no significant links between self-efficacy with neither of the criteria of leader effectiveness. Therefore, Hypothesis 2 was not supported.

Hypothesis 3 stated that the relationship between selfefficacy and leader effectiveness is mediated by transformational leadership. As leader effectiveness criteria leadership emergence, perceived leader effectiveness and group performance were used. Fig. 1 shows the mediation model we proposed. To examine hypothesis 3 , a nonparametric bootstrapping procedure to test the data for simple mediation was intended to use. As with other mediation analyses (i.e., [88]), it is informative to examine the association between variables in each pathway of the mediation model (Fig. 1), e.g., between (a) the independent variable and mediators, (b) mediator and dependent variable and (c) independent and dependent variable. As can be seen in Table II and Table III, correlation analyses do not show significant relationships between a leader's self-efficacy and transformational leadership and its dimensions. On the other hand, Table II shows that analyses confirmed a significant association between transformational leadership and all leader effectiveness criteria. Finally, results presented in Table II do not show significant relationships between the selfefficacy and leader effectiveness criteria.

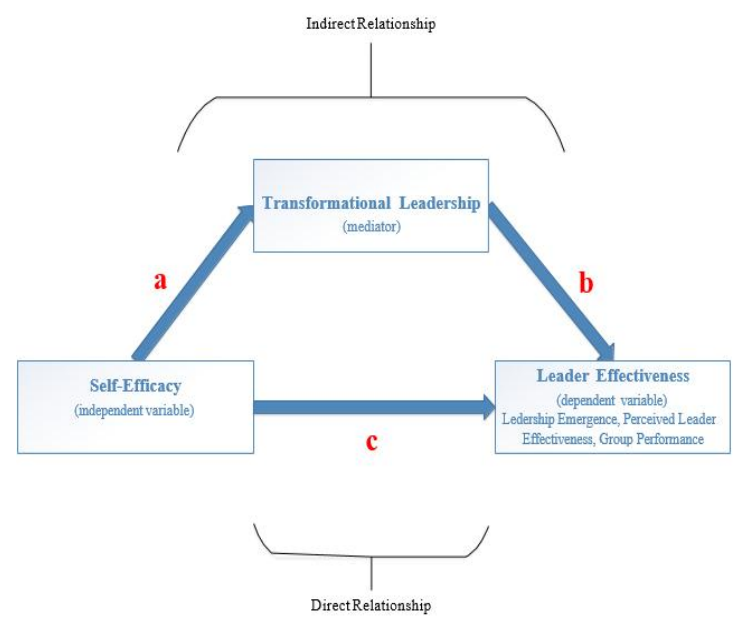

Figure 1. Simple mediation model

By definition, a mediator is a variable that is causally between independent and dependent variable. In the case of our data, results show that transformational leadership is not associated with both. While it was related to dependent variable leader effectiveness, independent variable self-efficacy did not associate with transformational leadership. Therefore, it can be assumed that transformational leadership is not a mediator of the relationship between self-efficacy of leaders and their effectiveness, without utilizing the bootstrapping method for the assessment of mediation. To conclude, Hypothesis 3 was therefore not supported.

TABLE III. CORRELATION COEFFICIENTS BETWEEN SELF-EFFICACY AND DIMENSIONS OF TRANSFORMATIONAL LEADERSHIP

\begin{tabular}{|l|c|c|c|c|c|c|c|}
\hline & \multicolumn{9}{|c|}{ Transformational leadership } \\
\hline & \multicolumn{2}{|c|}{ Charismatic behavior } & Inspirational motivation & \multicolumn{2}{|c|}{ Intelectual stimulation } & Individualized consideration \\
\hline Variable & $r$ & Sig. (2-tailed) & $r$ & Sig. (2-tailed) & $r$ & Sig. (2-tailed) & $r$ \\
\hline Self-efficacy & 0.11 & 0.55 & 0.10 & 0.60 & -0.15 & 0.41 & -0.09 \\
\hline
\end{tabular}

IV. DISCUSSION
The purpose of this study was to examine relationship between self-efficacy of leaders, their transformational leadership style and leader effectiveness within the 
management simulation game. The criteria of leader effectiveness, leadership emergence, perceived leader effectiveness and group performance were utilized. This research did not find support for the following links: (1) leaders' self-efficacy to the extent to which leaders' exhibit transformational leadership; (2) leaders' selfefficacy to leader effectiveness. Therefore, we did not find support for the mediation model, in which transformational leadership mediates relationship between leaders' self-efficacy and leader effectiveness.

As noted above, this research did not confirm the proposed mediation model with transformational leadership as a mediator of the link between leaders' self-efficacy and their effectiveness. We rejected this model because, on the contrary to the hypothesis, our study did not find a significant relation between leaders' self-efficacy and transformational leadership style. Our assumption that self-efficacy might have been an antecedent of transformational leadership, as individuals with high levels of efficacy are likely to take the initiative in challenging situations and persuade others to do the same, were based on theories of self-efficacy [56] and transformational leadership [42]. However, our presumption was not supported, despite of the results of studies linking these two constructs [75], [79]. This may be so for various reasons. Research shows that leaders with high self-efficacy set higher goals, which in turn lead to better group performance [68]. However, some high-efficacy leaders without a sufficient level of abilities might set goals too high and therefore make them unrealistic. In return, their followers may perceive them as neither influential nor charismatic leaders. On the other hand, leaders' high levels of self-efficacy might be related to overconfidence in their own abilities. Leaders could then make more decisions by themselves, giving less space to others. So, benefits of high self-efficacy can be counterbalanced by some disadvantages, which makes the relationship look like non-existent. Moreover, general self-efficacy refers to efficacies across different situations. Thus, it is possible that a person with high general self-efficacy may not have high efficacy in relation to the activities which he or she performs as a leader. Our sample consisted of students/leaders without experience. They were only gaining their experience during the game and ensuring themselves that they can be effective in a leader role. Perhaps, it would be more appropriate to use a leadership self-efficacy scale for this sample. Results of experienced leaders could also be different.

Even though our research did not find evidence of relationship between self-efficacy of leaders and leader effectiveness, this link might exist. Leaders who face tasks as a part of our management simulation game might perceive the situation at least partly through the lens of their beliefs in their own general capabilities. Their selfefficacy may then affect the way they are perceived by their followers (leadership emergence and perceived leader effectiveness) and might eventually play role in the objectively measurable organizational performance (group performance). Given Hayes [89] approach to mediation, direct relationship between self-efficacy and leader effectiveness criteria does not have to manifest significantly in the statistical analysis. Self-efficacy may have indirect effect on leader effectiveness through another variable. One theoretical explanation for our results might lay in the idea that a mediating mechanism may exist, linking leaders' self-efficacy and their effectiveness, but that mediating mechanism may not be transformational leadership behaviors. There might be other behaviors, which are indicative of the different types of contributions leaders make, but were not examined by this research. These behaviors might be the true mediators of the relationship. Some examples of these behaviors could be leader contributions to problem-solving or persuasive communication [77]. However, the findings of our research might not suggest that leader emergence, perceived leader effectiveness or group performance could be outgrowths of leader's self-efficacy.

Another explanation for our unconfirmed presumptions might lie in the way self-efficacy was captured. From the nature of general self-efficacy, it can be expected that it is unitary construct. For its assessment, we decided to use general Self-efficacy Scale [64]. This method was examined by Chen, Gully, and Eden [60], who suggested that a discrepancy may exist between the conceptualization of general self-efficacy as a unidimensional construct on one hand and the multifactorial structure of the general Self-efficacy Scale on the other. Although general self-efficacy has been conceived as unidimensional (e.g., [62], [63]) Woodruff and Cashman [90] found that items of general Self-Efficacy Scale measure three distinct empirical factors reflecting self-perceptions of behavior initiation, effort, and persistence. Woodruff and Cashman's findings were replicated by Bosscher and Smit [91] who found the same three-factor structure. Our findings may suggest that part of general self-efficacy of leaders might affect leader effectiveness in a positive way, but another part might have a negative impact. For instance, a leader with a high general self-efficacy may act with confidence and persistence, so his or her followers believe in the goal, which in turn might translate into better organizational performance. But, the same high-efficacy leader may seem in a sense overly capable, that he or she can handle everything, so the followers leave the important work and decisions on him or her, what then might have a negative impact on performance. Thus, three identified factors of general self-efficacy might have manifested in our results. For the future research, it may be useful to utilize the Bosscher's and Smit's [91] version of the general Selfefficacy Scale, which enables researchers to obtain values for three factors of general self-efficacy and subject them to analysis in order to determine their impact on leader effectiveness.

Furthermore, a limitation concerning the design of study might be a time when leaders' self-efficacy was assessed. The CEOs took part in psychodiagnostical testing at the end of a semester, a few days or week before the end of the game. Bosscher and Smit [91] stated that general self-efficacy is generated by various and numerous experiences of failure and success in different domains of functioning. Additionally, self-efficacy can also be moderated by feedback. CEOs were receiving information about their performance on regular basis 
throughout the game. Thus, the experience gathered during participation in the simulation and feedback they received during the game may have had effect on level of self-efficacy of CEOs. However, that would translate into higher levels of general self-efficacy for successful leaders and lower for those who were not so successful. Therefore, the examined relationship between self-efficacy and effectiveness would be stronger. As our results did not confirm this relationship, we do not assume that the time of measurement of self-efficacy affected validity of our research.

This research makes several methodological contributions. First of all, our study was conducted within a three-months-long management simulation game. This research design enabled us to reduce the impact of external variables and compare fictional companies, which were from the beginning on the same starting line. Thus, we were able to better monitor the possible impact of the CEO on his or her followers and the organizational outcomes. In comparison with real-world organizations, this simulation game allowed obtaining a large amount of data. Unlike short-term simulations, the three-months-long management simulation game made it possible to monitor how the CEO may or may not, through his or her personality and attitude, influence their subordinates for relatively longer time. Although there are undeniable advantages to the use of simulations in leadership research, it is also important to question possible drawbacks connected with the use of management simulation game. One potential argument against may be that the simulation game represents an unreal situation and is therefore only a game. An important issue associated with the use of games in general is the extent to which participants are truly engaged in the tasks of a game. Hackman [92], on behalf of engagement in simulations, notes that groups are expected to work particularly hard on tasks when the following conditions are met: the group task requires members to use a variety of high-level skills; the task is a whole, meaningful piece of work; outcomes have significant consequences for the organization; the task provides a high level of autonomy for the group; and work on the task generates regular, trustworthy feedback. The tasks used in the management simulation game met all of Hackman's [92] criteria for being engaging enough to be meaningful. Moreover, observations and small survey suggested that the majority of participants were highly engaged in their work on the simulation. Thus, the engagement of our respondents could be comparable to the involvement and enthusiasm of employees in the real organizational context.

In addition to this, we should mention the criterion of outcomes' significant consequences [92]. The final grade of each participant was dependent on outcomes of one's fictional company in the game. Within the area of responsibility of CEOs was to terminate the fictional employment of their employees if necessary, so negative outcomes might have had also consequences on individual level. However, as the termination of employment meant also failing the course, most leaders were hesitant to actually terminate someone's employment, because of their fear of jeopardizing future social contact with followers. Though, this fact does not automatically represent a limitation. On the contrary, in certain organization cultures, where relationships are more important than outputs, such as nonprofit organizations or public administration, an unwillingness to terminate employment of employees can be also present. Therefore, our findings could be generalized within certain organizational contexts, beyond the simulation game.

Another important issue which might abound in the context of simulations is the nature of the sample. All respondents in our research were students of bachelors and masters programs at two Czech universities. Their participation in the simulation game was a part of the academic course. The fact that the sample consisted of students exclusively gave the management simulation game a certain advantage in comparison to real-life organizations. We may say that the managements of fictional companies had approximately the same knowledge and experience. Thus, the environment of the management simulation game enabled us to better monitor the impact of characteristics on the performance of followers, especially the CEO's characteristics. However, we suggest assessing an amount and nature of previous work experience of the CEOs by several short questions in the future research, as it might differ among students of various enrollment years and affect the final results. An alternative solution might be zero to five months of previous work experience in leading position as a condition for inclusion in the research.

Additionally, the sample of students examined in this study consisted of newly formed groups, which represented management of fictional companies. Respondents did not have pre-established roles and also did not know each other very well prior to the start of their work on the tasks (as they were from different faculties or of different enrollment year). These groups did not have an initially designated leader either. Members of groups were asked to select their CEO from among themselves at the beginning of the game. Furthermore, the task our respondents worked on was very complex. Groups were operating under a great deal of time pressure and also knew that they would only be working together for a limited period of time. These points might seem as factors distinguishing our simulation from a real-life organizational environment. However, aforementioned points match a situation in various types of project teams in different organizations. Therefore, our findings might be applicable also for a team environment. Another important methodological contribution is the use of different types of leader effectiveness criteria. As criterions of leader effectiveness, we used both organizational measure (group performance) and subordinate measures of effectiveness (perceived leader effectiveness, leadership emergence).

According to Lowe, Kroeck, and Sivasubramaniam [24], there have been only a limited number of studies, which use both types of measures; usually they work with organizational outcomes measures or subordinates measures of leader and organizational effectiveness, but not both.

To conclude, there are some limitations associated with this research, ranging from issues of generalizability to methodological issues, as well as important contributions 
such as utilization of the management simulation game and the use of objective and subjective criteria for assessment of leader effectiveness in this research. Even though our assumptions about the nature of relationship between self-efficacy of leaders, transformational leadership style and leader effectiveness were not confirmed in this research, we would like to pursue the further research of self-efficacy and leadership behavior in the future. Future research would benefit from a research sample of larger size, which would allow us to control the impact of possible intervening variables, moderators and mediators in the model.

\section{ACKNOWLEDGMENT}

This article is a part of the research "Effective leadership: An integrative approach." The research has been funded by the Czech Science Foundation (P403/12/0249).

\section{REFERENCES}

[1] G. A. Yukl, Leadership in Organizations, Upper Saddle River, NJ: Prentice Hall, 2002.

[2] J. F. Cooper and J. Nirenberg, "Leadership effectiveness," in Encyclopedia of leadership, G. R. Goethals, G. J. Sorenson, and J. M. Burns, Eds. Thousand Oaks, CA: Sage, 2004, pp. 450-457.

[3] F. E. Fiedler and A. F. Leister, "Leader intelligence and task performance: A test of a multiple screen model," Organizational Behavior and Human Performance, vol. 20, no. 1, pp. 1-14, 1977.

[4] T. A. Judge, A. E. Colbert, and R. Ilies, "Intelligence and leadership: A quantitative review and test of theoretical propositions," Journal of Applied Psychology, vol. 89, no. 3, pp. 542-552, June 2004.

[5] R. G. Lord, C. L. De Vader, and G. M. Alliger, "A meta-analysis of the relation between personality traits and leadership perceptions: An application of validity generalization procedures," Journal of Applied Psychology, vol. 71, no. 3, pp. 402-410, Aug. 1986.

[6] D. Rosete and J. Ciarrochi, "Emotional intelligence and its relationship to workplace performance outcomes of leadership effectiveness," Leadership \& Organization Development Journal, vol. 26, no. 5, pp. 388-399, 2005.

[7] R. K. Hambleton and R. Gumpert, "The validity of Hersey and Blanchard's theory of leader effectiveness," Group \& Organization Management, vol. 7, no. 2, pp. 225-242, June 1982.

[8] T. A. Judge and R. Ilies, "Relationship of personality to performance motivation: A meta-analytic review," Journal of Applied Psychology, vol. 87, no. 4, pp. 797-807, Aug. 2002.

[9] T. A. Judge, J. E. Bono, R. Ilies, and M. W. Gerhardt, "Personality and leadership: A qualitative and quantitative review," Journal of Applied Psychology, vol. 87, no. 4, pp. 765-781, Aug. 2002.

[10] C. Silverthorne, "Leadership effectiveness and personality: A cross cultural evaluation," Personality and Individual Differences, vol. 30, no. 2, pp. 303-309, Jan. 2001.

[11] A. Romano, "Bracing for the gender neutral test," Newsweek, vol. 150, no. 23, pp. 13, Dec. 2007.

[12] A. Sullivan, "Gender bender," Time, vol. 24, p. 36, 2008.

[13] A. H. Eagly, S. J. Karau, and M. G. Makhijani, "Gender and the effectiveness of leaders: A meta-analysis," Psychological Bulletin, vol. 117, no. 1, pp. 125-145, Jan. 1995.

[14] J. Sweetland, Work in America Institute Studies in Productivity: Highlights of the Literature: Managerial Productivity, Scarsdale, NY: Work in America Institute, 1978.

[15] M. M. Chemers, "Leadership research and theory: A functional integration," Group Dynamics: Theory, Research, and Practice, vol. 4, no. 1, pp. 27-43, Mar. 2000.

[16] M. R. Frone, "Intolerance of ambiguity as a moderator of the occupational role stress strain relationship: A meta-analysis," Journal of Organizational Behavior, vol. 11, no. 4, pp. 309-320, July 1990.
[17] G. Harris and J. Hogan, "Perceptions and personality correlates of managerial effectiveness," in Proc. 13th Annual Psychology in the Department of Defense Symposium, Colorado Springs, CO, 1992.

[18] C. C. Bocchino, B. W. Hartman, and P. F. Foley, "The relationship between person-organization congruence, perceived violations of the psychological contract, and occupational stress symptoms," Consulting Psychology Journal: Practice and Research, vol. 55, no. 4, pp. 203-214, 2003.

[19] R. J. House, "A path goal theory of leader effectiveness," Administrative Science Quarterly, vol. 16, no. 3, pp. 321-339, Sept. 1971.

[20] S. Kerr and J. M. Jermier, "Substitutes for leadership: Their meaning and measurement," Organizational Behavior and Human Performance, vol. 22, no. 3, pp. 375-403, 1978.

[21] P. Hersey and K. H. Blanchard, Management of Organizational Behavior: Utilizing Human Resources, Englewood Cliffs, NJ: Prentice-Hall, Inc, 1982.

[22] V. H. Vroom and P. W. Yetton, Leadership and Decision-Making, Pittsburg: University of Pittsburgh, 1973.

[23] Y. Ling, Z. Simsek, M. H. Lubatkin, and J. F. Veiga, "Transformational leadership's role in promoting corporate entrepreneurship: Examining the ceo-tmt interface," Academy of Management Journal, vol. 51, no. 3, pp. 557-576, June 2008.

[24] K. B. Lowe, K. G. Kroeck, and N. Sivasubramaniam, "Effectiveness correlates of transformational and transactional leadership: A meta-analytic review of the mlq literature," The Leadership Quarterly, vol. 7, no. 3, pp. 385-425, 1996.

[25] B. van Knippenberg, D. van Knippenberg, D. De Cremer, and M. A. Hogg, "Research in leadership, self, and identity: A sample of the present and a glimpse of the future," The Leadership Quarterly, vol. 16, no. 4, pp. 495-499, Aug. 2005.

[26] S. A. Haslam, Psychology in Organizations, Thousand Oaks, CA: Sage, 2001.

[27] M. A. Hogg, "A social identity theory of leadership," Personality and Social Psychology Review, vol. 5, no. 3, pp. 184-200, 2001.

[28] D. Van Knippenberg and M. A. Hogg, Leadership and Power: Identity Processes in Groups and Organizations, Thousand Oaks, CA: Sage, 2004.

[29] R. Awamleh and W. L. Gardner, "Perceptions of leader charisma and effectiveness: The effects of vision content, delivery, and organizational performance," The Leadership Quarterly, vol. 10, no. 3, pp. 345-373, 1999.

[30] D. V. Day and J. Antonakis, The Nature of Leadership, Thousand Oaks, CA: Sage, 2012.

[31] J. F. Binning, A. J. Zaba, and J. C. Whattam, "Explaining the biasing effects of performance cues in terms of cognitive categorization," Academy of Management Journal, vol. 29, no. 3, pp. 521-535, Sept. 1986.

[32] B. J. Avolio, F. J. Yammarino, and B. M. Bass, "Identifying common methods variance with data collected from a single source: An unresolved sticky issue," Journal of Management, vol. 17, no. 3, pp. 571-587, Sept. 1991.

[33] J. Procházka and P. Smutný, "Four indicators of effective leadership," in Psychology of Work and Organization, E. Letovancová and E. Vavráková, Eds. Bratislava, SK: UKB, 2011, pp. 388-397.

[34] T. A. Judge, C. L. Jackson, J. C. Shaw, B. A. Scott, and B. L. Rich, "Self-efficacy and work-related performance: The integral role of individual differences," Journal of Applied Psychology, vol. 92, no. 1, pp. 107-127, Jan. 2007.

[35] D. L. Ford and M. I. Kiran, "Perceived leader effectiveness across organizational roles: Exploratory evidence from central Eurasia," Eurasian Journal of Business and Economics, vol. 1, no. 2, pp. 131-156, 2008.

[36] R. Hogan and R. B. Kaiser, "What we know about leadership," Review of General Psychology, vol. 9, no. 2, pp. 169-180, June 2005.

[37] E. P. Hollander, Leaders, Groups, and Influence, New York: Oxford U. Press, 1964.

[38] G. Yukl, "An evaluation of conceptual weaknesses in transformational and charismatic leadership theories," The Leadership Quarterly, vol. 10, no. 2, pp. 285-305, 1999.

[39] J. Antonakis, A. T. Cianciolo, and R. J. Sternberg, "Leadership: Past, present, and future," in The Nature of Leadership. London: Sage, 2004, pp. 3-15.

[40] J. Burns, Leadership, New York: Harper \& Row, 1978. 
[41] R. House, "A 1976 theory of charismatic leadership effectiveness," in Leadership: The Cutting Edge, J. G. Hunt and L. L. Larson, Eds. Carbondale: University Press, 1977, pp. 189-207.

[42] B. Bass, Leadership and Performance beyond Expectations, New York, NY: Free Press, 1985.

[43] B. M. Bass and R. E. Riggio, Transformational Leadership, Mahwah, NJ: Psychology Press, 2006.

[44] B. M. Bass, "From transactional to transformational leadership: Learning to share the vision," Organizational Dynamics, vol. 18, no. 3, pp. 19-31, 1990.

[45] B. M. Bass and B. J. Avolio, Improving Organizational Effectiveness through Transformational Leadership, Thousand Oaks, CA: Sage, 1994.

[46] T. A. Judge and R. F. Piccolo, "Transformational and transactional leadership: A meta-analytic test of their relative validity," Journal of Applied Psychology, vol. 89, no. 5, pp. 755-768, Oct. 2004.

[47] J. Barling, S. Moutinho, and E. Kelloway, Transformational Leadership and Group Performance: The Mediating Role of Affective Commitment, Kingston: Queens University, 2000.

[48] W. L. Koh, R. M. Steers, and J. R. Terborg, "The effects of transformational leadership on teacher attitudes and student performance in Singapore," Journal of Organizational Behavior, vol. 16, no. 4, pp. 319-333, July 1995.

[49] H. Yu, K. Leithwood, and D. Jantzi, "The effects of transformational leadership on teachers commitment to change in Hong Kong," Journal of Educational Administration, vol. 40, no. 4, pp. 368-389, 2002.

[50] B. M. Bass and B. J. Avolio, MLQ, Multifactor Leadership Questionnaire Sampler Set: Technical Report, Leader Form, Rater Form, and Scoring Key for MLQ Form $5 x$-Short, Mind Garden, 2000.

[51] T. Dvir, D. Eden, B. J. Avolio, and B. Shamir, "Impact of transformational leadership on follower development and performance: A field experiment," Academy of Management Journal, vol. 45, no. 4, pp. 735-744, Aug. 2002.

[52] R. J. Givens, "Transformational leadership: The impact on organizational and personal outcomes," Emerging Leadership Journeys, vol. 1, no. 1, pp. 4-24, 2008.

[53] P. Bycio, R. D. Hackett, and J. S. Allen, "Further assessments of Bass's (1985) conceptualization of transactional and transformational leadership," Journal of Applied Psychology, vol. 80, no. 4, pp. 468-478, Aug. 1995.

[54] J. B. Fuller, C. E. Patterson, K. Hester, and D. Y. Stringer, "A quantitative review of research on charismatic leadership," Psychological Reports, vol. 78, no. 1, pp. 271-287, Feb. 1996.

[55] A. Bandura, Social Foundations of Thought and Action, Englewood Cliffs, NJ: Prentice Hall, 1986.

[56] A. Bandura, Self-Efficacy: The Exercise of Control, New York: Macmillan, 1997.

[57] M. E. Gist and T. R. Mitchell, "Self-efficacy: A theoretical analysis of its determinants and malleability," Academy of Management Review, vol. 17, no. 2, pp. 183-211, Apr. 1992.

[58] A. D. Stajkovic and F. Luthans, "Self-efficacy and work-related performance: A meta-analysis," Psychological Bulletin, vol. 124, no. 2, pp. 240-261, Sept. 1998.

[59] R. Wood and A. Bandura, "Impact of conceptions of ability on self-regulatory mechanisms and complex decision making," Journal of Personality and Social Psychology, vol. 56, no. 3, pp. 407-415, Mar. 1989.

[60] G. Chen, S. M. Gully, and D. Eden, "Validation of a new general self-efficacy scale," Organizational Research Methods, vol. 4, no. 1, pp. 62- 83, Jan. 2001.

[61] D. Eden, "Means efficacy: External sources of general and specific subjective efficacy," in Work Motivation in the Context of a Globalizing Economy, M. Erez, U. Kleinbeck, and H. Thierry, Ed. Erlbaum, 2001, pp. 73-86.

[62] D. G. Gardner and J. L. Pierce, "Self-esteem and self-efficacy within the organizational context an empirical examination," Group \& Organization Management, vol. 23, no. 1, pp. 48-70, Mar. 1998.

[63] T. A. Judge, E. A. Locke, and C. C. Durham, "The dispositional causes of job satisfaction: A core evaluations approach," Research in Organizational Behavior, vol. 19, pp. 151-188, 1997.

[64] M. Sherer, J. E. Maddux, B. Mercandante, S. Prentice-Dunn, B. Jacobs, and R. W. Rogers, "The self-efficacy scale: Construction and validation," Psychological Reports, vol. 51, no. 2, pp. 663671, 1982.

[65] C. L. Hoyt, S. E. Murphy, S. K. Halverson, and C. B. Watson, "Group leadership: Efficacy and effectiveness," Group Dynamics: Theory, Research, and Practice, vol. 7, no. 4, pp. 259-274, Dec. 2003.

[66] M. M. Chemers, C. B. Watson, and S. T. May, "Dispositional affect and leadership effectiveness: A comparison of self-esteem, optimism, and efficacy," Personality and Social Psychology Bulletin, vol. 26, no. 3, pp. 267-277, Mar. 2000.

[67] L. L. Paglis and S. G. Green, "Leadership self-efficacy and managers' motivation for leading change," Journal of Organizational Behavior, vol. 23, no. 2, pp. 215-235, Mar. 2002.

[68] T. D. Kane, S. J. Zaccaro, T. R. Tremble, and A. D. Masuda, "An examination of the leaders regulation of groups," Small Group Research, vol. 33, no. 1, pp. 65-120, Feb. 2002.

[69] M. M. Chemers, "Efficacy and effectiveness: Integrating models of leadership and intelligence," in Multiple Intelligences and Leadership, R. E. Riggio, S. E. Murphy, and F. J. Pirozzolo, Ed. Mahwah, NJ: Erlbaum, 2002, pp. 139-160.

[70] M. D. Wisner, "Psychological strengths as predictors of effective student leadership," Christian Higher Education, vol. 10, no. 3-4, pp. 353-375, 2011.

[71] S. Raub and H. Liao, "Doing the right thing without being told: Joint effects of initiative climate and general self-efficacy on employee proactive customer service performance," Journal of Applied Psychology, vol. 97, no. 3, pp. 651-667, May 2012.

[72] T. L. Messer, "A study of general self-efficacy: Training, job performance, and attrition of novice Army* mechanics in a simulated work environment," Ph.D. dissertation, Spalding University, 2007.

[73] J. J. Martocchio and T. A. Judge, "Relationship between conscientiousness and learning in employee training: Mediating influences of self-deception and self-efficacy," Journal of Applied Psychology, vol. 82, no. 5, pp. 764-773, Oct. 1997.

[74] G. Chen, W. J. Casper, and J. M. Cortina, "The roles of selfefficacy and task complexity in the relationships among cognitive ability, conscientiousness, and work-related performance: A metaanalytic examination," Human Performance, vol. 14, no. 3, pp 209-230, 2001.

[75] K. Nielsen and F. Munir, "How do transformational leaders influence followers' affective well-being? Exploring the mediating role of self-efficacy," Work \& Stress, vol. 23, no. 4, pp. 313-329, 2009.

[76] R. Pillai and E. A. Williams, "Transformational leadership, selfefficacy, group cohesiveness, commitment, and performance," Journal of Organizational Change Management, vol. 17, no. 2, pp. 144-159, 2004.

[77] N. R. Quigley, "The relationship between leader core selfevaluations, team feedback, leader efficacy, transformational leadership, team efficacy, team goals, team action and transition processes, and team performance," Ph.D. dissertation, University of Maryland, 2003.

[78] S. A. Kirkpatick and E. A. Locke, "Leadership: Do traits matter?" Academy of Management Executive, vol. 5, no. 2, pp. 48-60, Feb. 1991.

[79] Y. Bo, "The influence study of transformational leadership in university on teachers' organizational commitment: The construction and verification of a theoretical model," Canadian Social Science, vol. 9, no. 4, pp. 126-137, 2013.

[80] S. Fitzgerald and N. S. Schutte, "Increasing transformational leadership through enhancing self-efficacy," Journal of Management Development, vol. 29, no. 5, pp. 495-505, 2010.

[81] L. Wang, "Sources of leadership self-efficacy: Follower feedback and group performance outcomes," International Journal of Business Research, vol. 7, no. 6, 2007.

[82] S. E. Murphy, "The contribution of leadership experience and selfefficacy to group performance under evaluation apprehension," Ph.D. dissertation, University of Washington, 1992.

[83] P. Smutny, J. Prochazka, and M. Vaculik, "Learning effectiveness of management simulation game Manahra," in Proc. 7th European Conference on Games Based Learning, C. V. de Carvahlo and P. Escudeiro, Ed. UK: Academic Conference and Publishing Limited, 2013, pp. 512-520. 
[84] D. M. Cable and T. A. Judge, "Pay preferences and job search decisions: A person-organization fit perspective," Personnel Psychology, vol. 47, no. 2, pp. 317-348, 1994.

[85] J. A. Smith and R. J. Foti, "A pattern approach to the study of leader emergence," The Leadership Quarterly, vol. 9, no. 2, pp. $147-160,1998$.

[86] P. Tharenou, S. Latimer, and D. Conroy, "How do you make it to the top? An examination of influences on women's and men's managerial advancement," Academy of Management Journal, vol. 37, no. 4, pp. 899-931, 1994.

[87] S. S. Shapiro and M. B. Wilk, "An analysis of variance test for normality (complete samples)," Biometrika, vol. 52, no. 3/4, pp. 591-611, 1965.

[88] R. M. Baron and D. A. Kenny, "The moderator-mediator variable distinction in social psychological research: Conceptual, strategic, and statistical considerations," Journal of Personality and Social Psychology, vol. 51, no. 6, pp. 1173-1182, Dec. 1986.

[89] A. F. Hayes, "Beyond Baron and Kenny: Statistical mediation analysis in the new millennium," Communication Monographs, vol. 76, no. 4, pp. 408-420, 2009.

[90] S. L. Woodruff and J. F. Cashman, "Task, domain, and general efficacy: A reexamination of the self-efficacy scale," Psychological Reports, vol. 72, no. 2, pp. 423-432, Apr. 1993.

[91] R. J. Bosscher and J. H. Smit, "Confirmatory factor analysis of the general self-efficacy scale," Behaviour Research and Therapy, vol. 36, no. 3, pp. 339-343, Mar. 1998.

[92] J. R. Hackman, "The design of work teams," Ariel, vol. 129, pp. 32-197, 1987.

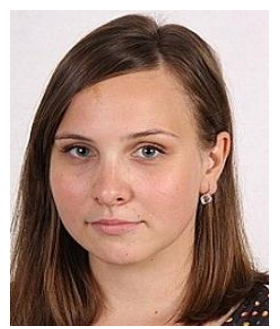

Jana Mesterova was born in Slovakia. She received the master degree in Psychology (MA equivalent, 2014) at Masaryk University, Brno, Czech Republic. This paper is based on her master thesis. She focuses on Work Psychology and Human Resource Management.

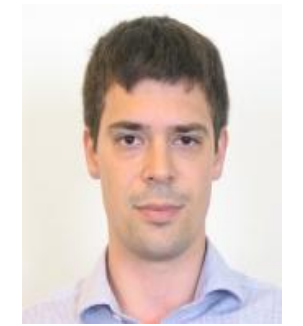

Jakub Prochazka was born in Czech Republic. He received the master degrees in Psychology (MA equivalent, 2008), in Finance (MSc equivalent, 2009) and the Ph.D in Social Psychology (2013) at Masaryk University, Brno, Czech Republic. He works as an Assistant Professor at the Department of Psychology and at the Department of Corporate Economy at Masaryk University, Brno, Czech Republic. His research focuses on prosocial behavior and on leadership. Dr. Prochazka is a member of European Association of Work and Organizational Psychology and an international affiliate of American Psychological Association.

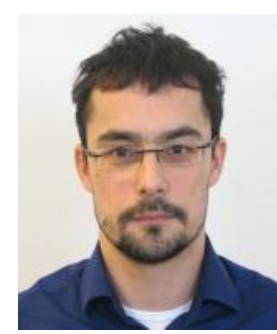

Martin Vaculik was born in Czech Republic. He received the master degree in Psychology (MA equivalent, 1998) and the Ph.D. in Social Psychology (2000) at Masaryk University, Brno, Czech Republic. He habilitated in Social and Work Psychology at Comenius University in Bratislava, Slovakia (2010). He works as an Associate Professor at the Department of Psychology, Masaryk University, Brno, Czech Republic. His research focuses on leadership, assessment centre and employee selection.

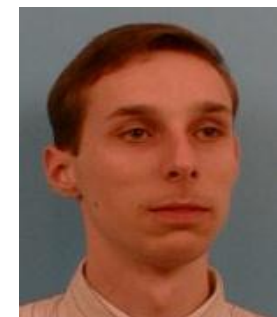

Petr Smutny was born in Czech Republic. He received the master degree in National Economy (MSc equivalent, 2001) and the Ph.D. in Management (2007) at Masaryk University, Brno, Czech Republic. He works as an Assistant Professor at the Department of Corporate Economy and as a vice-dean of Faculty of Economics and Administration, Masaryk University, Brno, Czech Republic. His research focuses on competency models, managerial skills and managerial simulation games. 